07

\title{
Использование солнечных элементов с двусторонней контактной сеткой в условиях Казахстана
}

\author{
(C) Н.С. Токмолдин, ${ }^{1}$ Н.А. Чучвага, ${ }^{1,2}$ В.Н. Вербицкий, ${ }^{3}$ Е.И. Теруков, ${ }^{3,4}$ А.С. Титов, ${ }^{3,4}$ \\ С.Ж. Токмолдин, ${ }^{1,2}$ К.С. Жолдыбаев ${ }^{1}$ \\ ${ }^{1}$ ТОО «Физико-технический институт», \\ 050032 Алматы, Республика Казахстан \\ ${ }^{2}$ Казахский национальный исследовательский технический университет им. К.И. Сатпаева, \\ 050013 Алматы, Республика Казахстан \\ ${ }^{3}$ Физико-технический институт им. А.Ф. Иофрфе РАН, \\ 194021 Санкт-Петербург, Россия \\ ${ }^{4}$ ООО «НТЦ Тонкопленочных технологий в энергетике», \\ 194064 Санкт-Петербург, Россия \\ e-mail: ntokmoldin@gmail.com
}

(Поступило в Редакцию 3 апреля 2017 г.)

Приведены результаты моделирования выходных характеристик кремниевых солнечных элементов на основе гетероперехода „кристаллический кремний-аморфный кремний“. Кроме того, проведена оценка перспективности использования двусторонних солнечных модулей в различных ориентационных конфигурациях. Для примера в качестве географического местоположения был выбран г. Астана, Казахстан, расположенный на $51.2^{\circ}$ северной широты и $71.4^{\circ}$ восточной долготы, на высоте $354 \mathrm{~m}$ над уровнем моря.

DOI: 10.21883/JTF.2017.12.45213.2274

\section{Введение}

Улучшения в технологиях изготовления солнечных элементов и модулей, произошедшие за последние несколько лет, позволили не только значительно повысить их эффективность и снизить себестоимость, но также расширить спектр их применения и придать им новые функциональные характеристики [1-4]. Одним из таких улучшений может выступить создание солнечных элементов и модулей, позволяющих генерировать электроэнергию при освещении как с фронтальной, так и с тыльной сторон [5]. Технологически этого можно добиться, исключив нанесение сплошного тыльного металлического контакта и используя вместо него такую же контактную сетку, как и с фронтальной стороны. Настоящая работа посвящена определению преимуществ изготовленных таким образом солнечных элементов и модулей.

\section{Методика эксперимента}

Для анализа характеристик солнечных элементов c двусторонней контактной сеткой была проведена оценка выходных характеристик подобных элементов в программном пакете „AFORS-HET“ при освещении их с лицевой и тыльной сторон излучением с интенсивностью $1000 \mathrm{~W} / \mathrm{m}^{2}$, соответствующим условиям AM1.5 [6-8]. Для этого был использован солнечный элемент на основе гетероперехода ,аморфный кремнийкристаллический кремний“ НIT (Heterojunction with Intrinsic thin layer) со следующими параметрами: толщина кристаллического слоя - $250 \mu \mathrm{m}$, толщина BSF (Black Surface Field) слоя и толщина собственного слоя, прилегающего к BSF, - $10 \mathrm{~nm}$, толщина эмиттерного слоя и толщина встроенного собственного слоя, прилегающего к эмиттерному, - $5 \mathrm{~nm}$; концентрация основных носителей заряда: эмиттерный слой $10^{20} \mathrm{~cm}^{-3}$, BSF слой $-10^{20} \mathrm{~cm}^{-3}$, кристаллический слой $-1.5 \cdot 10^{16} \mathrm{~cm}^{-3}$ (рис. 1). Для проникновения света с обеих сторон солнечного элемента на поверхность легированных аморфных кремниевых слоев помещались лицевой и тыльный прозрачный токопроводящий электроды ((TCO - Transparent Conductiviting Oxide) толщиной $80 \mathrm{~nm}$ на основе оксида индия, легированного оксидом олова (ITO).

Для оценки перспективности изготовления солнечных модулей, использующих элементы с контактной сеткой, нанесенной на лицевой и тыльной поверхностях, были проведены модельные эксперименты по оценке генерации электроэнергии солнечными модулями, состоящими из подобных элементов. Выбрано два способа расположения солнечных модулей. В конфигурации № 1 солнечные модули располагались под углом $45^{\circ}$, направлены на юг. В конфигурации № 2 модули располагались вертикально (под углом $90^{\circ}$ относительно поверхности земли) так, чтобы фронтальная сторона была направлена на восток, а тыльная на запад.

В исследовании были использованы следующие предположения:

1) в качестве модельной системы использовались 99 модулей размером порядка $1600 \times 800 \mathrm{~mm}$, совместно занимающих площадь $125 \mathrm{~m}^{2}$ и имеющих номинальную мощность системы $22.77 \mathrm{kWp}$;

2) коэффициент полезного действия (КПД) солнечных модулей при стандартных условиях был выбран равным $18.33 \%$; 


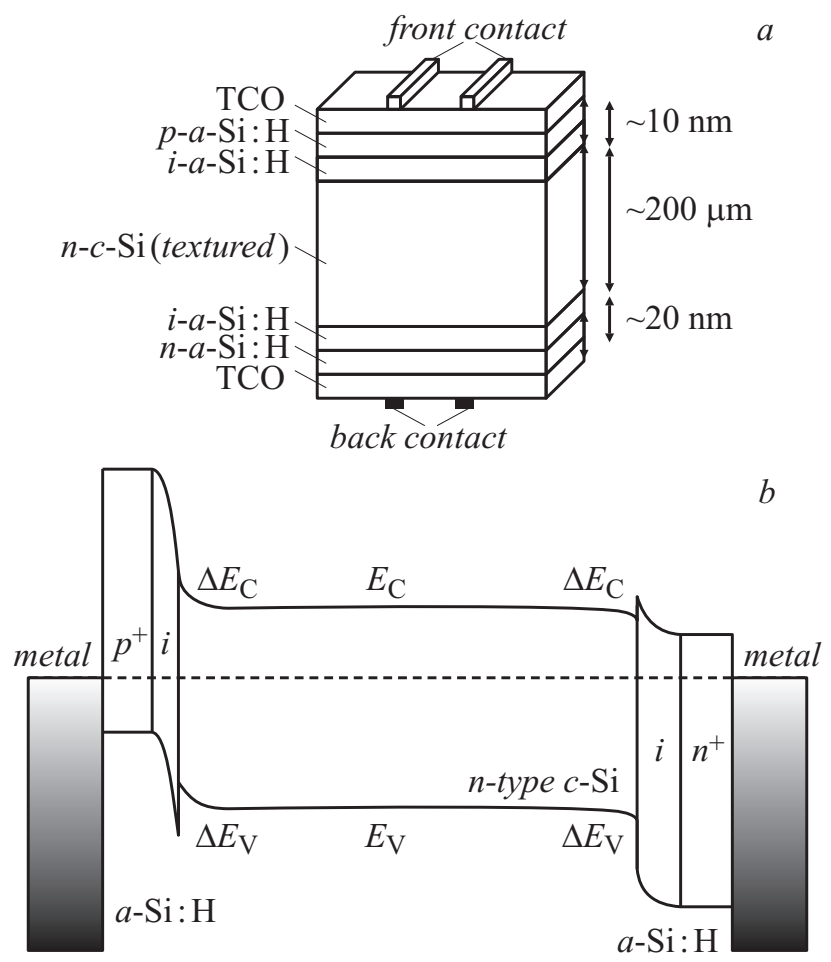

Рис. 1. Принципиальная схема $(a)$ и зонная диаграмма $(b)$ фотовольтаической структуры НІТ на основе полупроводникового перехода между аморфным кремнием и кристаллическим кремнием.

3) в качестве географического местоположения был выбран г. Астана, Казахстан, расположенный на 51.2 северной широты и $71.4^{\circ}$ восточной долготы, на высоте $354 \mathrm{~m}$ над уровнем моря [9].

Расчеты были сделаны основываясь на результатах работы [9].

\section{Результаты и обсуждения}

На рис. 2-4 представлены выходные характеристики описанного выше солнечного элемента HIT: квантовая эффективность, вольт-амперная характеристика и вольтмощностная характеристика.

При рассмотрении зависимости внешней квантовой эффективности солнечного элемента от длины волны падающего излучения при освещении его с лицевой и тыльной сторон (рис. 2, $a$ ) видно, что при освещении с тыльной стороны количество электронов, достигающих внешней электрической цепи, незначительно превышает таковое при освещении с лицевой стороны во всем диапазоне измерения. Разница в значениях квантовой эффективности возрастает для фотонов с большей энергией (меньшей длиной волны). Это, по всей видимости, связано с тем, что более высокоэнергетичные фотоны, имеющие более высокий коэффициент поглощения (рис. 3), поглощаются/рассеиваются рань- ше, чем низкоэнергетичные при прохождении сквозь солнечный элемент.

Очевидно, что электрон-дырочная пара, образуемая у тыльной поверхности фотоэлемента, удалена от области $p-i-n$-перехода по сравнению с электрон-дырочной парой, образуемой у лицевой поверхности. Соответственно первая электрон-дырочная пара имеет более высокую вероятность рекомбинации. Это, в конечном итоге, влияет на количество электронов, достигающих внешней электрической цепи, и на значение внешней квантовой эффективности. Квантовая эффективность солнечного
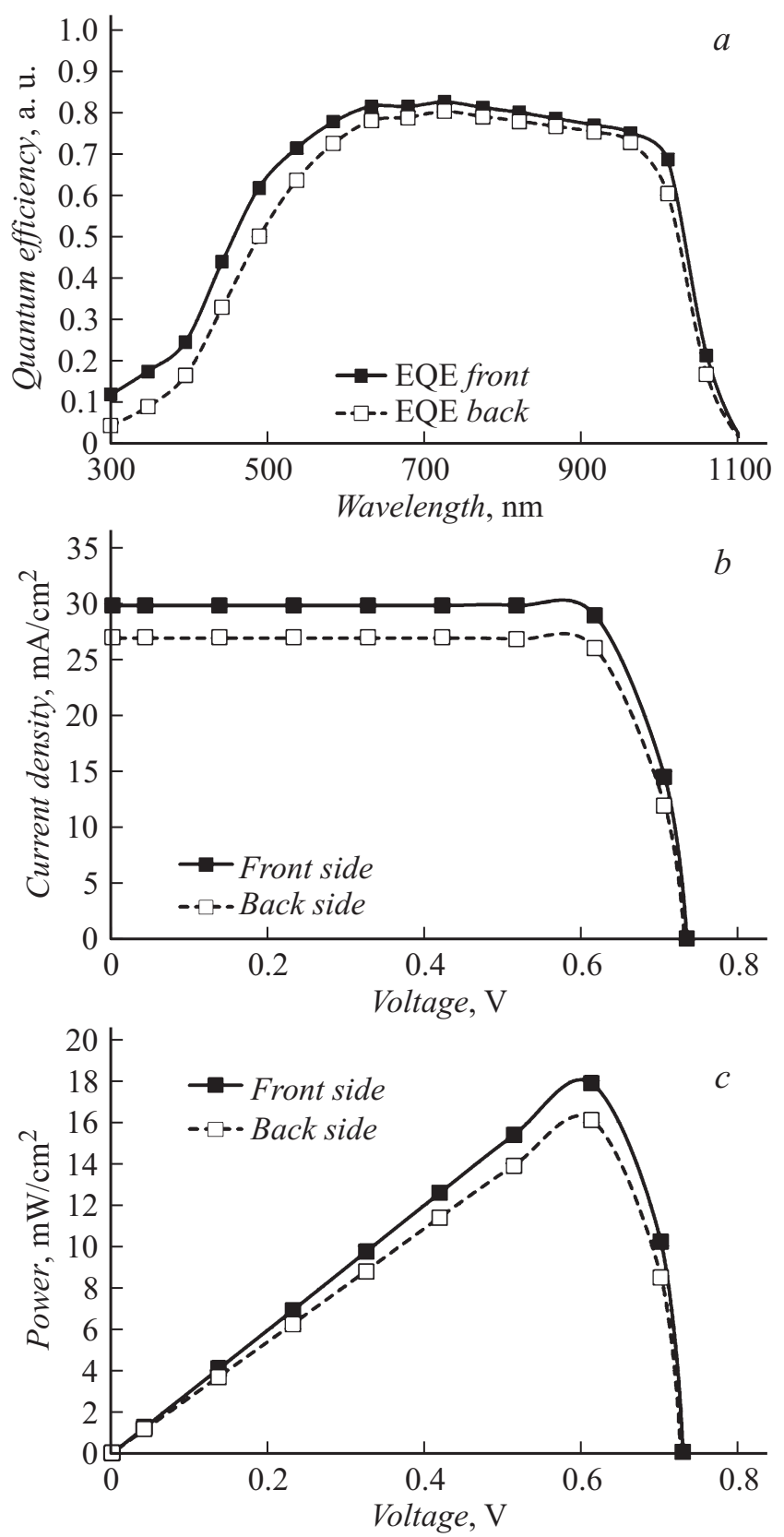

Рис. 2. Сравнение внешней квантовой эффективности $(a)$, вольт-амперных $(b)$ и мощностных $(c)$ характеристик солнечного элемента НIT при освещении его с лицевой (сплошная линия) стороны и тыльной (прерывистая линия). 
элемента связана с его током короткого замыкания выражением

$$
J_{\mathrm{AM} 1.5, \text { diode }}=e \int_{0}^{\infty} I P C E_{\mathrm{cell}}(\lambda) I_{\mathrm{AM} 1.5}(\lambda) d \lambda,
$$

где $J_{\mathrm{AM} 1.5, \text { diode }}-$ ток короткого замыкания диода, $e-$ заряд электрона, $\lambda$ - длина волны падающего излучения, $I P C E_{\text {cell }}(\lambda)$ - зависимость квантовой эффективности солнечного элемента от длины волны падающего излучения, $I_{\mathrm{AM} 1.5}(\lambda)$ - зависимость интенсивности падающего излучения от длины волны для стандартизированного солнечного спектра на поверхности Земли АM1.5 [10].

При этом можно ожидать, что ток короткого замыкания при освещении элемента с тыльной стороны будет меньше, чем при освещении с лицевой стороны. Это подтверждается ВАХ (рис. 2, $b$ ) и зависимостью мощности, выделяемой на солнечном элементе от напряжения прибора (рис. 2,c). Однако, как видно, разница в генерации носителей при освещении с тыльной или лицевой сторон и соответственно в токе короткого замыкания незначительна, составляя всего около 10\%. Эта разница связана с тем, что при освещении солнечного элемента с тыльной стороны носители, образуемые в начале пути, должны проделать больший путь для достижения области $p-i-n$-перехода, чем носители, образуемые при освещении с тыльной стороны. Такая разница может быть намного существеннее при использовании в качестве кристаллической кремниевой пластины материала с меньшим временем жизни неосновных носителей и соответственно меньшей длиной свободного пробега таких носителей. Таким образом, можно ожидать, что при использовании таких материалов, как поликристаллический кремний, применение двусторонних солнечных элементов может быть нецелесообразным.



Рис. 3. Зависимость коэффициента поглощения от длины волны для кристаллического кремния.
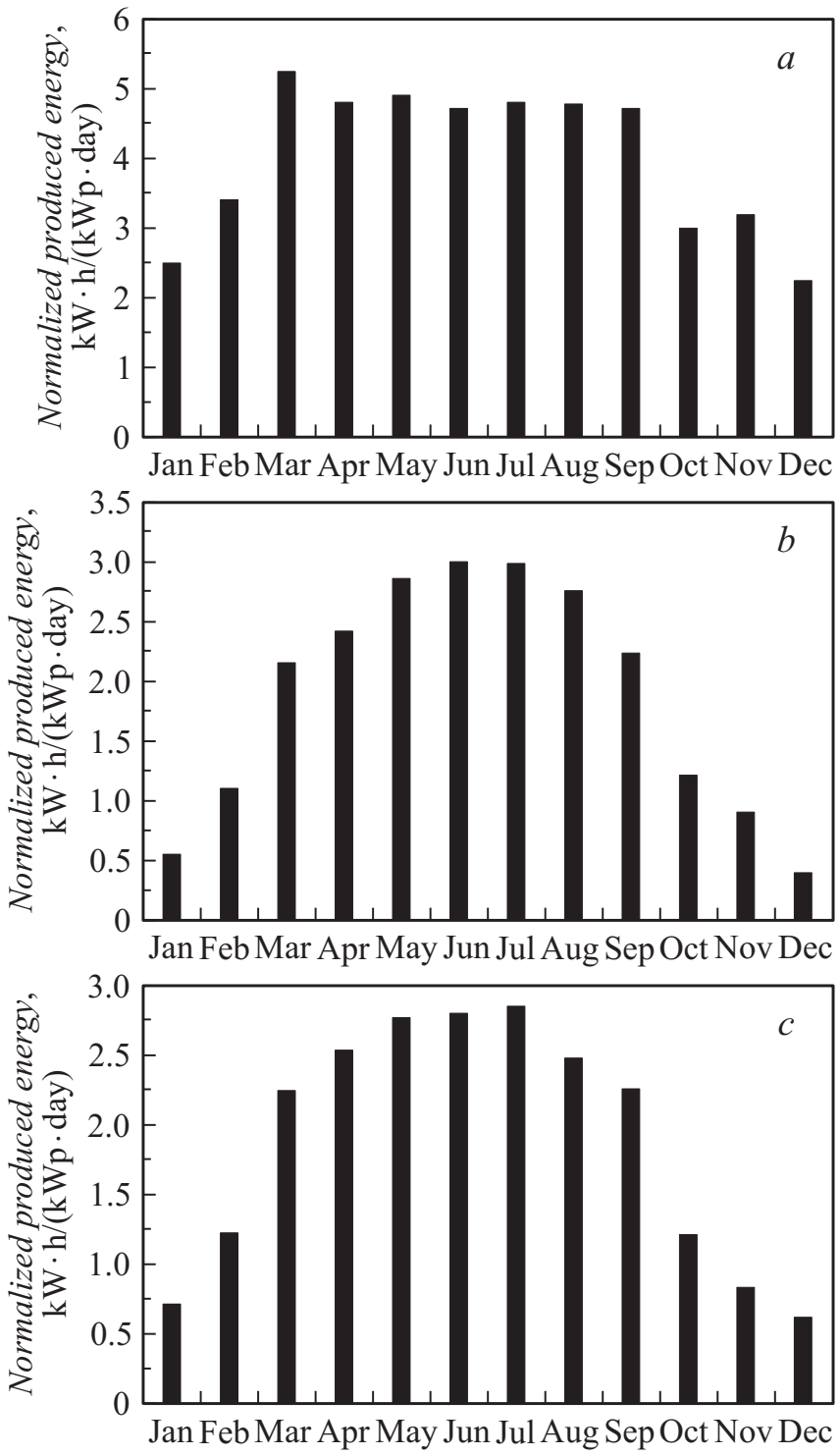

Рис. 4. Производство электроэнергии в течение года солнечными элементами, расположенными в конфигурации № 1 (a); выработка конфигурации № 2 электроэнергии для стороны солнечного элемента по направлению на восток $(b)$ и на запад $(c)$. Эффективность выработки в конфигурации № 1 1481, № $2-1382 \mathrm{~kW} \cdot \mathrm{h} /(\mathrm{kWp}$ · year).

\section{Преимущества использования двусторонних солнечных модулей}

Было обнаружено, что система двусторонних солнечных элементов/модулей, расположенных в конфигурации № 1, способна производить ежегодно $33.73 \mathrm{~kW} \cdot \mathrm{h}$ электроэнергии, что соответствует эффективности выработки $1481 \mathrm{~kW} \cdot \mathrm{h} /(\mathrm{kWp} \cdot$ year $)$. Данный показатель демонстрирует перспективность солнечной электрогенерации в рассматриваемой локации при сравнении с соответствующими значениями для Германии $(1000 \mathrm{~kW} \cdot \mathrm{h} /(\mathrm{kWp} \cdot$ year $))$ и Японии $(1400 \mathrm{~kW} \cdot \mathrm{h} /(\mathrm{kWp} \cdot$ year $))$. Нормализованные зна- 



Рис. 5. Производство электроэнергии в течение суток солнечными элементами в один из солнечных дней, выпадающих на каждый из двенадцати месяцев в течение года.

чения произведенной электроэнергии в единицах $[\mathrm{kW} \cdot \mathrm{h} /(\mathrm{kWp} \cdot \mathrm{year})]$ по месяцам в течение одного года приведены на рис. 4, $a$.

При рассмотрении двусторонних солнечных модулей, использующих солнечные элементы с контактной сеткой, нанесенной на лицевой и тыльной поверхностях, и расположенных в конфигурации № 2 (рис. $4, b, c)$, наблюдалось уменьшение суммарной выработки по сравнению с конфигурацией № 1 с величины $1481 \mathrm{~kW} \cdot \mathrm{h} /(\mathrm{kWp} \cdot$ year $)$ до величины $1382 \mathrm{~kW} \cdot \mathrm{h} /(\mathrm{kWp} \cdot$ year $)$.

Однако преимущества конфигурации № 2 по сравнению с конфигурацией № 1 становятся очевидными при рассмотрении почасовой выработки электроэнергии в течение дня (рис. 5). На рис. 5 показано сравнение почасового производства электроэнергии солнечными

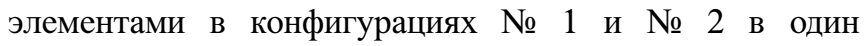

из солнечных дней, выпадающих на каждый из двенадцати месяцев в течение года. Условно, производство электроэнергии в конфигурации № 2 имеет два пика, приходящихся на 11 и $16 \mathrm{~h}$ в зимнее время и на 8 и $18 \mathrm{~h}$ в летнее время. Очевидно, что суммарная генерация для конфигурации № 2 в летнее время превосходит суммарную генерацию для конфигурации № 2 и приходится на наиболее энергоемкие периоды суток - утро и вечер, что идеально соответствует потребностям домохозяйств. В зимние периоды, однако, конфигурация № 1 имеет неоспоримое преимущество перед конфигурацией № 2, генерируя в любое время суток аналогичное, либо превосходящее количество электроэнергии.

Таким образом, можно предположить, что наиболее оптимальным вариантом использования двусторонних солнечных элементов и модулей с контактной сеткой, нанесенной на лицевой и тыльной поверхностях, являет- 
ся поочередное применение комбинации № 1 в зимнее время, и комбинации № 2 в летнее время.

\section{Заключение}

В настоящей работе представлены результаты моделирования выходных характеристик двусторонних гетеропереходных кремниевых солнечных элементов и модулей. Продемонстрировано, что генерация носителей заряда с лицевой и тыльной сторон двусторонних гетеропереходных кремниевых солнечных элементов на основе монокристаллического кремния отличается незначительно. Для оценки перспективности изготовления солнечных модулей, использующих элементы с контактной сеткой, нанесенной на лицевой и тыльной поверхностях, были проведены модельные эксперименты по оценке генерации электроэнергии солнечными модулями, состоящими из подобных элементов, установленными как в стандартной статической конфигурации с наклоном под углом $45^{\circ}$ по направлению к югу, так и в вертикальной статической конфигурации по направлению на восток и запад. Продемонстрировано, что суммарная генерация электроэнергии для последней конфигурации в летнее время превосходит суммарную генерацию для первой конфигурации и приходится на наиболее энергоемкие периоды суток - утро и вечер, что идеально соответствует потребностям домохозяйств. Однако в зимние периоды стандартная конфигурация демонстрирует превосходящую генерацию электроэнергии по сравнению с вертикальной конфигурацией. Мы надеемся, что результаты настоящей работы позволят подобрать наиболее оптимальные режимы работы двусторонних солнечных элементов в течение года в географических локациях, близких по характеристикам солнечного освещения республике Казахстан.

\section{Список литературы}

[1] Perrin C.B., Spatially J. // J. Phys. D. Appl. Phys. 1991. Vol. 24. P. 865.

[2] Bartlome R., Feltrin A., Ballif C. // Appl. Phys. Lett. 2009. Vol. 94. P. 201-501.

[3] Mitsuharu Konuma, Plasma Techniques for Film Deposition.: Alpha Science, 2005.

[4] Matsuda $A$ etal. // Solar Energy Materials \& Solar Cells. 2003. Vol. 78. P. 3-26.

[5] Mishima T. et al. // Solar Energy Materials \& Solar Cells. 2011. Vol. 945. P. 18-21.

[6] Stangl R., Kriegel M., Schmidt M. // IEEE 4th World Conf. on Photovoltaic Energy Conference. Vol. 2. IEEE, 2006. P. 13501353.

[7] Froitzheim A. etal. // Proc. of the World Conference on. Vol. 1. IEEE, 2003. P. 279-282.

[8] Stangl R., Leendertz C., Haschke J. // Sol. Energy. InTech. 2010. P. 319-352.

[9] Kryuchenko Yu.V. etal. // Energy Policy. 2014. Vol. 68. P. 116-122.

[10] Gueymard C., Myers D., Emery K. // Solar Energy. 2002. Vol. 73. N. 6. P. $443-467$. 